in New York in June-July, and the maximum number occur in March. Dr. Hess now informs me that the calcium content of the blood follows the same curve as the phosphorus content. Among earlier noted seasonal effects of sunlight, quoted by Hess in his latest paper, are the presence of increased iodine in the thyroid of cattle from June to November, and the greater resistance of guinea-pigs to aceto-nitrile poisoning in summer.

Hess and his workers have also begun the study of various clothing materials in this connexion, and find that they vary in their power of permitting or obstructing the action of light. Specimens of a mercerised cotton, one white and the other black, otherwise identical, the former allowing light to act and the latter interfering with it, have been examined by me, and I find no difference, due to the black dye, in the spacing between the fibres of the material. But I understand that the Department of Applied Physiology of the Medical Research Council has found, in a series of observations as yet unpublished, that the biological action of light can be graded by temperature. I am in hope that these specimens of material may be studied by the delicate methods associated with the name of Prof. Leonard Hill, and that it may be found that the black material produces a higher temperature than the white of the subjacent skin, thus prejudicing those unknown and beneficent chemical reactions which appear to need light and cold for their development.

The belief grows upon me that the asserted futility of heliotherapy in phthisis is due to the overheating of the patients in the sun. I think that a new chapter will open in the treatment of that disease when practitioners acquaint themselves with the principles and practice of heliotherapy before exposing their patients to the sun.

The power of sunlight and of cod-liver oil in rickets has suggested to Prof. Harden that the light may cause the skin to produce vitamin A for itself-though no instance of the synthesis of a vitamin by the animal body is known. The most recent work at the Lister Institute shows that light is unable to replace vitamin A completely, but appears to make a small quantity more effective. Miss Coward's work shows that vitamin $A$ is present in the parts of flowers which contain carotin. Sir William Bayliss has suggested to me that the production of this vitamin in green plants is a function of the carotin rather than of chlorophyll, and that probably the carotin acts as a sensitiser for ultra-violet rays. In this connexion we must remember that pigmentation of the skin is a marked feature of the sun-cure, and that patients who do not pigment well do not progress well. No one who has seen and touched the typical pigmented skin of a heliotherapeutic patient can doubt that very active chemical processes are there occurring. Perhaps we should regard the skin less as a mere integument than as an organ of internal secretion. The pigmented skin under the sunlight is surely that; and we may ask whether it contributes, as Sheridan Delépine suggested, ${ }^{5}$ to the making of hæmoglobin. I owe also to Sir William Bayliss the information that Dr. H. H. Dale, a member of his committee, has shown that smooth muscle can be made to contract by ultra-violet rays.

Aerial and other photographs of Manchester, and the Potteries, and of Sheffield, taken at successive hours on Sunday and Monday, demonstrate the obstruction of sunlight by our urban smoke, the industrial and the domestic chimney being both responsible : but while Sheffield deprives itself of more than half its sunlight, Essen is absolutely smokeless, and Pittsburg, which I have visited for the purposes of this inquiry, has abolished 85 per cent. of its smoke. Sections of the lungs of an agricultural labourer and a typical urban inhabitant of our country, the latter being. heavily infiltrated with smoke, illustrate a cognate aspect of our subject.

Yet another point is illustrated by recent work of Hess, which shows that the milk of cows fed on pasture in the sunlight maintains the growth and health of young animals, whereas the milk of cows fed in shadow and on vitamin-free fodder will not maintain life. Our children are thus disadvantaged in winter by light-starvation, and by the defect of the milk of lightstarved cows. ${ }^{6}$

Photographic study, of houses and housing on both sides of the Atlantic illustrates the problem of urban light-starvation. Finding New York smokeless in I919, I later made investigations with the aid of Dr. Royal S. Copeland, the Health Commissioner of that city, and found that the death-rate from pulmonary tuberculosis had been reduced by one-half in the period, 1905-1919, of the operation of the sanitary regulation against smoke. ${ }^{7}$ The restoration of sunlight to our urban lives is the next great task of public health in this country.

"There is no darkness but ignorance," as Shakespeare said. In every sense we need "more light." Then we must apply our knowledge, less for heliotherapy than heliohygiene, until we have banished what I call the diseases of darkness, and it may be said of us that "The people that walked in darkness have seen a great light, and they that dwell in the land of the shadow of death, upon them hath the light shined."

5 Journal of Physiology, vol. xii., I89 I, p. 27

列 New Zealand, comes to the rescue.

" The smoke prohibited in New York, or in Winnipeg, where I found similar regulations, need not, as in our futile Public Health Act, be " black." See "The Eugenic Prospect " (Part II., "Let There Be Light"), by Dr. York, I92I.)

\title{
Domestic Animals in Relation to Diphtheria.
}

THE perennial alarm of the possible transmission of diphtheria from diseased animals to man is again occupying the attention of the British daily press. This time it arose out of the death of a little girl who was thought by her mother to have contracted diphtheria from certain chickens which were kept in the house. The mother's view was supported by a medical man, who said that birds are subject to the germs of diph- theria and die of the disease. He had no doubt also that dogs and cats could have diphtheria, and he knew of instances of pigeons which had it.

The present writer has recently made an exhaustive critical analysis of the literature on this subject, and can state definitely that this bird, cat, and dog story is a pure myth. Diphtheria bacilli have been found on three occasions in cows (cases of Dean and Todd (I902), 
Ashby (1906), and Henry (1920)), and by two authors (Cobbett (I900) and Minnett (I920)) in horses. No proved diphtheria bacilli have ever been found occurring spontaneously in cats, dogs, or fowls. In 1920 Simmons obtained, from two cats, bacilli resembling diphtheria bacilli in man, but differing in the fundamental respect that they fermented cane sugar, which human diphtheria bacilli do not.

The belief that cats are frequently capable of transmitting diphtheria arose in Great Britain largely out of work done by $\mathrm{E}$. Klein for the Local Government Board in 1889 and 1890 . He based his opinion on the existence of spontaneous diphtheria in cats on the fact that a very fatty condition was found in the kidneys, a lesion which he regarded as pathognomonic of the disease in this animal. Before Klein published this statement it was already well known (Gluge (I850), Handfield Jones (I853), and Beale (I869)) that all normal cats show this lesion-a fact confirmed by modern writers like Hansemann (1897), Fibiger (I901), and Mottram (19r $5^{-16)}$. In an extensive inquiry in I9r9-20, Savage was unable to find, nor could any one produce, a cat infected with diphtheria bacilli.

The doctrine of milk-borne diphtheria was also largely based on Klein's work (I890). He alleged that when cows are injected with cultures of diphtheria bacilli in the shoulder, these diphtheria bacilli appear in the milk and the animals suffer from an eruptive disease of the udders and teats. Dean and Todd (I902) traced a milk-borne epidemic of diphtheria to cows with scabs on the udders. They showed that the eruption was not due to diphtheria, and they regarded the diphtheria bacilli found in the udder as a superposed infection from the saliva of an infected milker. In I920 Henry studied an epidemic of thirty-two cases. The disease was traced to milk. The dairy-maid was found to be suffering from cutaneous diphtheria, and from her the udder became affected, this in turn transferring the disease to the hands of the maid's father.

So far as is known, these are all the positive facts of the animal transmission of diphtheria to man. We may therefore assume that it is an event of exceeding rarity. With regard to birds there is no proved instance that these animals have ever transmitted the disease. So-called croup and diphtheritis in birds have nothing to do etiologically with human diphtheria. It is not necessary to assume an animal origin of an outbreak of diphtheria until all possible human sources in the immediate neighbourhood have been excluded. This can be done only by cultivations, and not by the pious opinions of mothers and medical men without experience in bacteriology.

\section{Obituary.}

\section{Prof. E. Majewski.}

THE HE late Prof. Erazm Majewski, the Polish naturalist, who died on November $r_{5}$ last in Warsaw, was a scholar and pioneer worker of a type characteristic of the difficult and discouraging conditions in pre-War Poland - a country divided by three alien states, two of which forbade the use of the native language, even in the primary schools, excluded native teachers, and suppressed native culture.

Born in 1858 , in the provincial town of Lublin, Prof. Majewski studied science at the University of Warsaw. In order to devote himself to research, to which he had felt attracted from earliest youth, he had first to gain a financial independence, for at that time there were no endowments, no academic positions, no possibilities of scientific publication for a Pole who wanted to work in his own language and for his own country. Prof. Majewski took up and developed an important branch of chemical industry and thus obtained a living at first, and afterwards what, for Polish conditions, might be considered a small fortune. With this he could not only find leisure for his own research, which soon became very strenuous and extensive, but he also was able to finance research and help a number of younger students.

Prof. Majewski's own activities were astoundingly multifarious : translations into Polish, popular expositions, manuals, monographs, scientific novels, treatises, and last, not least, solid original contributions, partly based on research in the laboratory and in the field. The subjects of his work were commensurately extensive: chemistry, botany and geology; later on, ethnography, prehistory and archæology; finally, in the last ten years of his life, economics, sociology, and history of civilisation. Perhaps the most lasting value will be retained by his archæological and prehistoric studies, through the impetus which he gave to excavation and collecting, through the foundation of an excellent periodical (Sroiatowit), which he financed and edited himself, and through the formation of a large and valuable collection of Slavonic archæology, presented in I92 I to the Scientific Society of Warsaw.

All Prof. Majewski's work reveals a man of genius in the marvellous grasp of each problem touched upon, in the original and independent point of view, in the amazing power of study and assimilation. It shows, of course, also the defects of its qualities: such enormous output over a wide range is bound to entail a certain degree of dilettantism, many hasty generalisations, and a tendency to avoid all negative evidence. All the defects of the late Prof. Majewski's work, however, are due mainly to the unfavourable conditions under which he worked : absence of scientific organisation, of co-operation and of division of work, all of which leads to the unlimited pegging out of claims over the vast territory of science by an enterprising and independent mind, to lack of self-criticism, to an easy lapsing into over-ambitious schemes. The qualities which he possessed, on the other hand, are native and intrinsic to his own mind, and entitle us to hope that his country, which can produce such people as he under the most discouraging conditions, will, when its political and economic foundations are once more secure and its scientific work organised, be able to contribute its due share to the progress of science.

B. M.

\section{Dr. Hartwig Franzen.}

ON February I4 the death occurred at Karlsruhe, Baden, of Dr. Hartwig Franzen, extraordinary professor of organic chemistry at the Technical High School. 